\title{
Acúmulo de nutrientes no colmo de cana-de-açúcar em função de fontes e doses de manganês
}

\section{Amount of nutrients in stalk of sugar cane as a function of sources and doses of manganese}

\author{
Cleiton Gredson Sabin Benett ${ }^{1 *}$; Salatiér Buzetti ${ }^{2}$; Katiane Santiago Silva Benett ${ }^{3}$; \\ Marcelo Carvalho Minhoto Teixeira Filho²; Nídia Raquel Costa"; \\ Alexandra Sanae Maeda ${ }^{5}$; Marcelo Andreotti ${ }^{2}$
}

\begin{abstract}
Resumo
A baixa produtividade dos canaviais em algumas áreas pode estar relacionada a exigência e exportação da cultura da cana-de-açúcar. O objetivo deste estudo foi avaliar o efeito de cinco doses e três fontes de manganês aplicadas no sulco de plantio na cultura da cana-de-açúcar em cana planta e seu efeito residual em cana soca. O experimento foi conduzido no sítio Fujimoto, área administrada pela Destilaria Vale do Paraná S/A Álcool e Açúcar, no município de Suzanápolis - SP. O delineamento experimental utilizado foi o de blocos ao acaso arranjado em esquema fatorial $5 \times 3$, sendo cinco doses de manganês $\left(0 ; 2,5 ; 5,0 ; 7,5\right.$ e $\left.10,0 \mathrm{~kg} \mathrm{ha}^{-1}\right)$ e três fontes (sulfato de manganês, quelato e FTE BR 12), aplicadas no sulco de plantio, com 4 repetições. As parcelas foram constituídas por 4 linhas de $5 \mathrm{~m}$ de comprimento, espaçadas por $1,5 \mathrm{~m}$. A variedade utilizada foi a RB 86-7515. Foi avaliado o acúmulo de macro e micronutrientes nos colmos, matéria seca de colmos e produtividade de colmos. As fontes e doses de manganês influenciaram no acúmulo de macro e micronutrientes e na matéria seca de colmo em cana planta e cana soca. A produtividade de colmos não foi influenciada pelas doses e fontes manganês em nenhum dos cultivos.
\end{abstract}

Palavras-chave: Saccharum spp., extração, produtividade

\begin{abstract}
The low productivity of sugarcane crop in some areas can be correlated with the lack of nutrients due to cane sugar crop be a major exporter of nutrients. The objective this study was to evaluate the effect of five doses and three sources of manganese applied in the planting furrow in sugar cane plant and its residual effects on ratoon cane, in the northwest region of São Paulo. The experiment was conducted at the site Fujimoto, area administered by the Valley Distillery Parana S/A Sugar and Alcohol in Suzanápolis - SP. The experimental design was randomized blocks in a factorial scheme $5 \times 3$, with five doses of manganese $\left(0,2.5,5.0,7.5\right.$ and $\left.10.0 \mathrm{~kg} \mathrm{ha}^{-1}\right)$ and three sources (sulfate, chelate and FTE), applied at planting furrow in 4 repetitions. The plots consisted of four rows $5 \mathrm{~m}$ long, spaced by 1.5 $\mathrm{m}$. The variety used was RB 86-7515. We assessed the accumulation of macro and micronutrients in stems, dry matter yield of stalks and stems. The sources and doses of manganese influenced the accumulation of macro and micronutrients and the dry stalks of sugar cane plant and ratoon cane. The stalk productivity was not affected by doses and sources of manganese in any crops.
\end{abstract}

Key words: Saccharum spp., extraction, productivity

1 Dr. Bolsista DCR/Desenvolvimento Científico e Tecnológico Regional, FAPEG/CNPq, Goiânia, GO. E-mail: cbenett@hotmail.com

2 Profs. Drs. da Universidade Estadual Paulista, UNESP/FE, Campus de Ilha Solteira, SP. E-mail: sbuzetti@agr.feis.unesp.br; mcmtf@yahoo.com.br; dreotti@agr.feis.unesp.br

3 Prof ${ }^{\mathrm{a}}$. Dr ${ }^{\mathrm{a}}$ da Universidade Estadual de Goiás, UEG/UUI, Unidade Universitária de Ipameri, GO. E-mail: kasantiago@ig.com.br

4 Discente de Doutorado em Agronomia/Sistema de produção, UNESP/FE, Campus de Ilha Solteira, SP. E-mail: nidiamagrela@ hotmail.com

5 Prof $^{\mathrm{a}}$. Dr ${ }^{\mathrm{a}}$ da Universidade Católica Dom Bosco, UCDB, Campus de Campo Grande, MS. E-mail: bele.maeda@hotmail.com Autor para correspondência 


\section{Introdução}

A cana-de-açúcar (Saccharum spp.) tem grande importância no setor socioeconômico do país, principalmente na produção de açúcar e etanol. A produção de cana na safra 2010/2011 foi de aproximadamente 623 milhões de toneladas em 8 milhões de hectares (CONAB, 2011).

É uma planta C4 que se adapta às diversas condições climáticas (SEGATO; MATTIUZ; MOZAMBANI, 2006) com desenvolvimento em forma de touceira e sua parte área é formada por colmos, folhas, inflorescências e frutos e a subterrânea por raízes e rizomas (MAZAMBANI et al., 2006).

A quantidade de nutrientes extraídos do solo e acumulados pelas plantas varia com a cultivar, manejo do solo, ciclo da cultura e dos nutrientes disponíveis para o desenvolvimento das plantas. Para os micronutrientes, o manganês, é o segundo mais extraído do solo pela cultura e a falta desse nutriente pode causar problemas na produtividade.

As quantidades de nutrientes absorvida e incorporada pela cultura da cana-de-açúcar são conhecimentos fundamentais para o estudo da adubação, indicando as quantidades de nutrientes a serem fornecidas (COLETI et al., 2006). Assim, em solos de baixa fertilidade ou que são explorados durante muitos anos, a ocorrência de deficiência de micronutrientes torna-se ainda mais agravada (CASARIN; VILLA NOVA; FORLI, 2001).

As plantas necessitam tanto de macro quanto de micronutrientes, visto que esses elementos desempenham funções vitais em seu metabolismo. Porém, a utilização de micronutrientes em canade-açúcar ainda apresenta muitas controvérsias (VAZQUEZ; SANCHES, 2010).

A quantidade de nutrientes extraída por uma tonelada de cana é de 1,$20 ; 0,36 ; 1,48 ; 1,12$; 0,68 e $0,36 \mathrm{~kg}$ de $\mathrm{N}, \mathrm{P}_{2} \mathrm{O}_{5}, \mathrm{~K}_{2} \mathrm{O}, \mathrm{CaO}, \mathrm{MgO}$ e $\mathrm{S}$, respectivamente (MALAVOLTA; VITTI; OLIVEIRA., 1997). Assim, a cultura da cana-de- açúcar tem grande potencial de extrair nutrientes do solo e acumular na parte aérea da planta.

A absorção de micronutrientes pela canade-açúcar é influenciada por diversos fatores, destacando-se a idade da planta, o tipo de solo e a variedade considerada. As curvas de absorção de micronutrientes permitem a definição das épocas em que as demandas são maiores. De maneira geral, em termos de exportação pelos colmos tem-se que: $\mathrm{Fe}>\mathrm{Mn}>\mathrm{Zn}$ (ORLANDO FILHO; ROSSETO; CASAGRANDE, 2001).

O manganês por ser o segundo micronutriente mais exigido pela cultura da cana-de-açúcar, atua na fotossíntese, sendo envolvido na estrutura, funcionamento e multiplicação de cloroplastos, também realiza o transporte eletrônico (VITTI; OLIVEIRA; QUINTINO, 2006), é requerido para a atividade de algumas desidrogenases, descarboxilases, quinases, oxidases e peroxidases.

Objetivou-se com este estudo avaliar o efeito de cinco doses e três fontes de manganês aplicadas no sulco de plantio de cana planta e seu efeito residual em cana soca, na região Noroeste do Estado de São Paulo.

\section{Material e Métodos}

O experimento foi conduzido no sítio Fujimoto, com coordenadas $20^{\circ} 32^{\prime} \mathrm{S}$ e $50^{\circ} 58^{\prime} \mathrm{O}$, e altitude de 361 metros, área administrada pela Destilaria Vale do Paraná S/A Álcool e Açúcar, no município de Suzanápolis - SP, situada no Noroeste do estado de São Paulo. O solo da área experimental é classificado como Argissolo Vermelho Eutrófico (EMBRAPA, 2006). Os atributos químicos do solo foram determinadas antes da instalação do experimento, segundo metodologia proposta por Raij et al. (2001), cujos resultados da análise química estão apresentados na Tabela 1 e a análise granulométrica na camada de 0 a $25 \mathrm{~cm}$ apresentou valores de 820,56 e $124 \mathrm{~g} \mathrm{~kg}^{-1}$ de areia, silte e argila, respectivamente. 
Tabela 1. Resultados da análise química e granulométrica do solo na área experimental, antes do plantio da cana. Suzanápolis-SP, 2007.

\begin{tabular}{|c|c|c|c|c|c|c|c|c|c|c|}
\hline \multirow{2}{*}{$\begin{array}{l}\text { Camada } \\
(\mathrm{cm})\end{array}$} & $\begin{array}{c}\mathrm{P} \\
\text { (resina) }\end{array}$ & M.O. & $\mathrm{pH}$ & $\mathrm{K}$ & $\mathrm{Ca}$ & $\mathrm{Mg}$ & $\mathrm{H}+\mathrm{Al}$ & SB & CTC & V \\
\hline & $\mathrm{mg} \mathrm{dm} \mathrm{m}^{-3}$ & $\mathrm{~g} \mathrm{dm}^{-3}$ & $\mathrm{CaCl}_{2}$ & \multicolumn{6}{|c|}{---------------------mmol $\mathrm{dm}^{-3}$----------------- } & $\%$ \\
\hline $0-25$ & 3,0 & 24,0 & 4,9 & 3,0 & 10,0 & 8,0 & 20,0 & 21,4 & 41,4 & 52,0 \\
\hline $25-50$ & 2,0 & 12,0 & 4,6 & 0,3 & 9,0 & 4,0 & 21,0 & 13,3 & 34,3 & 39,0 \\
\hline \multirow{2}{*}{$\begin{array}{c}\text { Camada } \\
(\mathrm{cm})\end{array}$} & \multicolumn{2}{|c|}{$\mathrm{Cu}^{*}$} & \multicolumn{2}{|c|}{$\mathrm{Fe}^{*}$} & \multicolumn{2}{|c|}{$\mathrm{Mn} *$} & \multicolumn{2}{|c|}{$\mathrm{Zn*}$} & \multicolumn{2}{|c|}{ B** } \\
\hline & \multicolumn{10}{|c|}{ 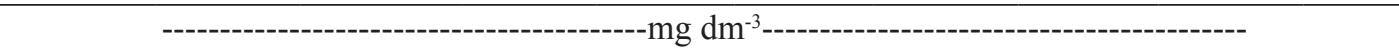 } \\
\hline $0-25$ & \multicolumn{2}{|c|}{0,8} & \multicolumn{2}{|c|}{13,0} & \multicolumn{2}{|c|}{4,8} & \multicolumn{2}{|c|}{0,4} & \multicolumn{2}{|c|}{0,61} \\
\hline $25-50$ & \multicolumn{2}{|c|}{0,9} & \multicolumn{2}{|c|}{8,0} & \multicolumn{2}{|c|}{2,5} & \multicolumn{2}{|c|}{0,1} & \multicolumn{2}{|c|}{0,50} \\
\hline
\end{tabular}

* Determinado em DTPA; ** Água quente. Análise química realizada no Laboratório de Fertilidade do Solo UNESP/FE.

Fonte: Elaboração dos autores.

O clima da região é classificado como Aw pela classificação de Köppen, com temperatura média anual de $23,7^{\circ} \mathrm{C}$ e precipitação pluvial média anual de $1300 \mathrm{~mm}$.

O delineamento experimental utilizado foi o de blocos ao acaso no esquema fatorial $3 \times 5$, sendo 3 fontes de manganês: Quelato (7\% Mn), FTE BR 12 pó $(1,8 \% \mathrm{~B} ; 0,8 \% \mathrm{Cu} ; 3,0 \% \mathrm{Fe} ; 2,0 \% \mathrm{Mn} ; 0,10 \%$ Mo e $9,0 \% \mathrm{Zn})$ e Sulfato de manganês (31\% Mn e $18 \% \mathrm{~S})$ e 5 doses de manganês $(0 ; 2,5 ; 5,0 ; 7,5$ e $10,0 \mathrm{~kg} \mathrm{ha}^{-1}$ ), aplicadas no sulco de plantio, com 4 repetições. O FTE foi utilizado para se verificar o seu efeito residual, já que é um produto de baixa solubilidade, e analisar a sua capacidade de fornecimento de outros micronutrientes à cana de açúcar, já que foram analisados, além do $\mathrm{Mn}$, o $\mathrm{B}, \mathrm{Cu}, \mathrm{Fe}$ e $\mathrm{Zn}$. Como o solo estava deficiente em $\mathrm{Zn}$, aplicaram-se em todos os tratamentos, $5 \mathrm{~kg}$ $\mathrm{ha}^{-1}$ de sulfato de zinco. Os tratamentos fontes e doses foram aplicados apenas no sulco de plantio, imediatamente antes do plantio da cana planta. As parcelas foram constituídas por 4 linhas de $5 \mathrm{~m}$ de comprimento, espaçadas por 1,5 m. No preparo do solo foram realizadas uma aração profunda e aplicação de $2 \mathrm{t} \mathrm{ha}^{-1}$ de calcário, conforme análise do solo.

A variedade da cana-de-açúcar utilizada foi a RB 86-7515 de ciclo médio a tardio, alta velocidade de crescimento, porte alto, hábito de crescimento ereto, alta densidade de colmo e fácil despalha, cujo plantio foi realizado em 17 de março de 2008, adotandose o sistema de plantio manual (convencional), em que os toletes foram distribuídos dentro dos sulcos de plantio, sendo colocados seis toletes com três gemas em cada metro de sulco. As colheitas foram realizadas sem queima e manualmente, sendo a cana planta colhida dia 08 de julho de 2009 e a primeira soca em 05 de julho de 2010.

A cultura recebeu adubação de plantio com 30, 150 e $120 \mathrm{~kg} \mathrm{ha}^{-1}$ de $\mathrm{N}, \mathrm{P}_{2} \mathrm{O}_{5}$ e $\mathrm{K}_{2} \mathrm{O}$, respectivamente, conforme descrito por Raij et al. (1997). Na cana soca (primeira soca) foi realizada a aplicação de macronutrientes com 80 e $60 \mathrm{~kg} \mathrm{ha}^{-1}$ de $\mathrm{N}$ e $\mathrm{K}_{2} \mathrm{O}$, respectivamente, também de acordo com as recomendações de Raij et al. (1997), aplicados nas entre linhas da cultura aos 77 dias após a primeira colheita da cana planta.

Foram analisados os teores de macronutrientes $(\mathrm{N}, \mathrm{P}, \mathrm{K}, \mathrm{Ca}, \mathrm{Mg}$ e S) e micronutrientes (B, Fe, Mn e Zn) dos colmos, conforme Malavolta, Vitti e Oliveira (1997). Foram coletados sete colmos aleatórios de 10 colhidos no momento da colheita e posteriormente triturados. Retirou-se uma amostra desse material triturado e colocado em estufa de circulação de ar forçada para secar com temperatura de $65^{\circ} \mathrm{C}$, até massa em equilíbrio.

Para a obtenção dos valores de macro e micronutrientes extraídos nos colmos, foram 
quantificados os teores de nutrientes, segundo descrito em Malavolta, Vitti e Oliveira (1997) e calculando-se os teores em $\mathrm{kg} \mathrm{ha}^{-1}$.

A massa da matéria seca de colmos foi realizada através da coleta de sete colmos industrializáveis, onde se retirou a palhada e os colmos foram triturados e posteriormente levados para secar em estufa com circulação de ar forçada, com temperatura de 65 ${ }^{\circ} \mathrm{C}$, por cerca de 72 horas ou massa em equilíbrio, calculando-se a massa da matéria seca em toneladas por hectare.

A produção de colmos por hectare foi determinada contando-se o número de colmos da área útil da parcela, cortando-se dez colmos industrializáveis por parcela, pesando-se e calculando-se a produtividade em tonelada de cana por hectare.

Os dados foram submetidos à análise de variância pelo (teste F) e quando as médias apresentavam nível de significância foi comparada pelo teste de Tukey a $5 \%$ de probabilidade para fontes e para as doses de Mn foram realizadas análises de regressão. As análises estatísticas foram processadas utilizando o programa de Análise Estatística - SANEST (ZONTA; MACHADO; SILVEIRA JÚNIOR, 1987).

\section{Resultados e Discussão}

Na Tabela 2 são apresentados os valores médios de N, P e K no colmo em cana planta e cana soca. Quando se avaliaram as fontes de Mn observaramse efeito significativo apenas para os teores de $\mathrm{N}$ em cana planta, onde a fonte FTE BR 12 proporcionou maior acúmulo de $\mathrm{N}$ nos colmos. A aplicação de manganês além de ser importante na produção de clorofila e carboidratos, influencia também no metabolismo do nitrogênio para as plantas, já que a redutase do nitrito contém $\mathrm{Mn}$.

Tabela 2. Acúmulo médio de macronutrientes $(\mathrm{N}, \mathrm{P}$ e K) nos colmos em função de fontes e doses de manganês na cultura da cana-de-açúcar. Suzanápolis-SP, 2009 e 2010.

\begin{tabular}{|c|c|c|c|c|c|c|}
\hline \multirow{3}{*}{ Tratamentos } & \multicolumn{3}{|c|}{ Cana planta } & \multicolumn{3}{|c|}{ Cana soca } \\
\hline & $\mathrm{N}$ & $\mathrm{P}$ & $\mathrm{K}$ & $\mathrm{N}$ & $\mathrm{P}$ & $\mathrm{K}$ \\
\hline & \multicolumn{3}{|c|}{$\mathrm{kg} \mathrm{ha}^{-1}$} & \multicolumn{3}{|c|}{$\mathrm{kg} \mathrm{ha}^{-1}$} \\
\hline \multicolumn{7}{|l|}{ Fontes de Mn } \\
\hline Quelato & $87,97 \mathrm{~b}$ & $6,48 \mathrm{a}$ & $86,31 \mathrm{a}$ & $92,72 \mathrm{a}$ & $11,31 \mathrm{a}$ & $115,70 \mathrm{a}$ \\
\hline FTE BR 12 & $102,14 \mathrm{a}$ & $5,80 \mathrm{a}$ & $77,76 \mathrm{a}$ & 89,49 a & $11,44 \mathrm{a}$ & $128,16 \mathrm{a}$ \\
\hline Sulfato de Manganês & $87,32 \mathrm{~b}$ & $6,79 \mathrm{a}$ & $79,18 \mathrm{a}$ & $86,67 \mathrm{a}$ & $9,91 \mathrm{a}$ & $123,65 \mathrm{a}$ \\
\hline \multicolumn{7}{|l|}{ Doses de $\mathrm{Mn}\left(\mathrm{kg} \mathrm{ha}^{-1}\right)$} \\
\hline 0 & 83,55 & 5,70 & 75,88 & 83,86 & 8,93 & 101,21 \\
\hline 2,5 & 92,87 & 6,21 & 82,56 & 83,89 & 10,26 & 105,25 \\
\hline 5,0 & 91,74 & 7,07 & 73,83 & 84,76 & 9,78 & 125,43 \\
\hline 7,5 & 95,12 & 6,89 & 86,90 & 99,66 & 13,70 & 168,73 \\
\hline 10,0 & 99,09 & 5,91 & 86,24 & 95,96 & 10,75 & 111,91 \\
\hline $\mathrm{CV}(\%)$ & 9,52 & 29,88 & 15,94 & 9,68 & 22,38 & 13,94 \\
\hline
\end{tabular}

Médias seguidas pela mesma letra, na coluna, não diferem entre si pelo teste de Tukey a 5\% de probabilidade.

Fonte: Elaboração dos autores. 
Resultados encontrados por Mendes (2006) estudando o acúmulo de nutrientes em sete variedades de cana-de-açúcar constatou que a RB 867515 extraiu $150 \mathrm{~kg} \mathrm{ha}^{-1}$ de N, com produtividade de $155 \mathrm{t} \mathrm{ha}^{-1}$. Barbosa et al. (2002) estudando a cultivar RB 72-454 em cana planta observaram remoção de $134 \mathrm{~kg} \mathrm{ha}^{-1}$ e Coleti et al. (2002) avaliando o acúmulo de $\mathrm{N}$ na SP 81-3250 constataram para cana planta extração de $207 \mathrm{~kg} \mathrm{ha}^{-1}$ de N, resultados esses superiores aos encontrados neste trabalho.

Nas avaliações das doses de Mn nos colmos de cana planta e cana soca, ocorreu efeito significativo para os valores de $\mathrm{N}$ acumulado em cana planta e cana soca (Figura 1a), com ajustes às regressões lineares crescentes com teores de 85,81 a 99,14 $\mathrm{kg} \mathrm{ha}^{-1}$ e 81,63 a 97,62 $\mathrm{kg} \mathrm{ha}^{-1}$, respectivamente. Oliveira (2008), trabalhando com diferentes cultivares de cana-de-açúcar, observou que a RB $86-7515$ acumulou nos colmos cerca de $141,21 \mathrm{~kg}$ $\mathrm{ha}^{-1}$ de $\mathrm{N}$, com produtividade de $168 \mathrm{t} \mathrm{ha}^{-1}$. Coleti et al. (2006) trabalhando com a cultivar SP 813250 e Oliveira et al. (2010) com a RB 86-7515, observaram acúmulo de 185 e $135 \mathrm{~kg} \mathrm{ha}^{-1}$ de $\mathrm{N}$, respectivamente, sendo esses valores superiores aos encontrados neste trabalho devido à uma baixa produtividade da cultivar RB 86-7515.

Figura 1. Acúmulo médio de $\mathrm{N}$ nos colmos em cana planta e cana soca (a) e valores de $\mathrm{K}$ em cana soca (b) em função das doses de manganês na cultura da cana-de-açúcar. Suzanápolis-SP, 2009 e 2010.

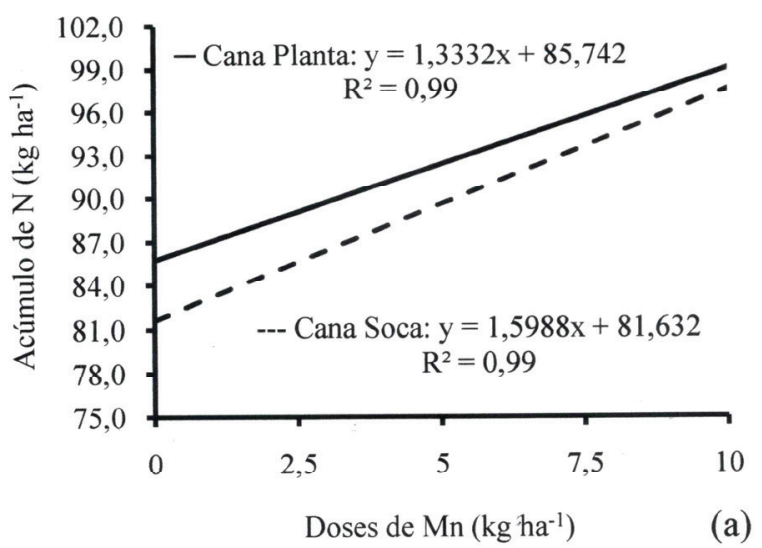

Fonte: Elaboração dos autores.

$\mathrm{O}$ acúmulo de $\mathrm{K}$ nos colmos em cana soca se ajustaram à regressão quadrática com ponto de máximo estimado em $6,97 \mathrm{~kg} \mathrm{ha}^{-1}$ de $\mathrm{Mn}$, com valor de K extraído de 136,21 $\mathrm{kg} \mathrm{ha}^{-1}$ (Figura 1b). O efeito significativo no acúmulo de $\mathrm{K}$ para as doses e Mn se deve a possível ocorrência do sinergismo entre o K x Mn. Esses resultados são superiores aos encontrados por Gomes (2003) que trabalhando com dois tipos de solo e doze cultivares em Porto FelizSP observou valores máximos de $\mathrm{K}$ extraídos de $107,27 \mathrm{~kg} \mathrm{ha}^{-1}$ na cultivar RB 82-5336 em cana soca,

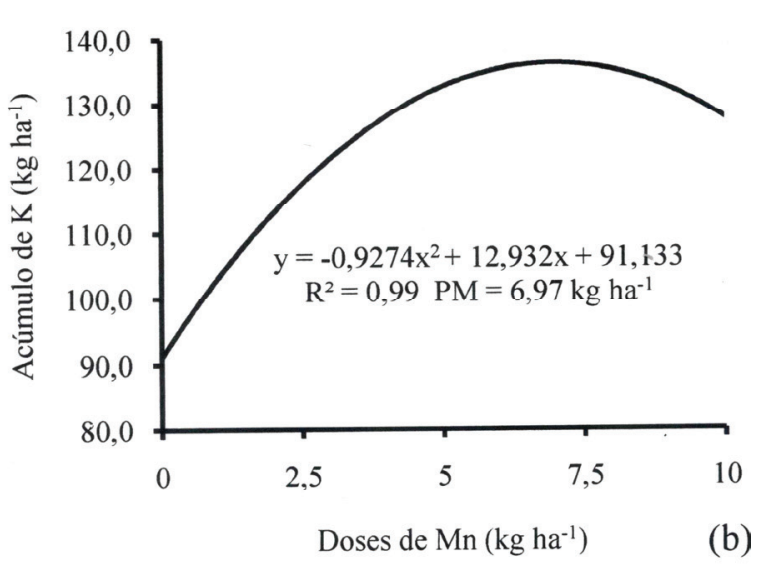

com produtividade de $69 \mathrm{t} \mathrm{ha}^{-1}$. Franco et al. (2008) verificaram acúmulo nas duas áreas (PirassunungaSP e Jaboticabal-SP) analisadas com de 214 a 285 kg para 100 toneladas de colmos industrializáveis.

Os dados referentes ao acúmulo de $\mathrm{Ca}, \mathrm{Mg}$ e $\mathrm{S}$ nos colmos em cana planta e cana soca são apresentados na Tabela 3. Ao analisar as fontes de Mn, observouse somente efeito significativo para o acúmulo de $\mathrm{Mg}$ em cana planta e cana soca, onde a fonte FTE BR 12 apresentou os maiores valores em relação às demais fontes. Essa significância pode ser explicada 
devido à presença de outros micronutrientes na fonte FTE interagindo com o $\mathrm{Mg}$ proporcionando, assim, maior absorção deste macronutriente.

Para as doses de Mn observou-se interação para fontes e doses quanto ao acúmulo de $\mathrm{Ca}$ e $\mathrm{Mg}$ em cana planta (Figura 2a, b). Para o acúmulo de $\mathrm{Ca}$, as fontes FTE BR 12 (FTE) e quelato se ajustaram à regressão linear crescente e os dados referentes à fonte sulfato de manganês se ajustaram à regressão quadrática com ponto de máximo estimado em 8,55 $\mathrm{kg} \mathrm{ha}^{-1}$ de Mn (Figura 2a). Silva (2007) avaliando a extração de Ca pela RB 86-7515 constatou valores médios de $13 \mathrm{~kg} \mathrm{ha}^{-1}$.

Já para o acúmulo de $\mathrm{Mg}$, as fontes FTE BR 12 e sulfato de manganês se ajustaram à regressão linear crescente, enquanto que a fonte quelato se ajustou à regressão quadrática com ponto de máximo estimado em 6,83 $\mathrm{kg} \mathrm{ha}^{-1}$ de Mn (Figura 2b).

Tabela 3. Acúmulo médio de macronutrientes $(\mathrm{Ca}, \mathrm{Mg}$ e $\mathrm{S})$ nos colmos em função de fontes e doses de manganês na cultura da cana-de-açúcar. Suzanápolis-SP, 2009 e 2010.

\begin{tabular}{|c|c|c|c|c|c|c|}
\hline \multirow{3}{*}{ Tratamentos } & \multicolumn{3}{|c|}{ Cana planta } & \multicolumn{3}{|c|}{ Cana soca } \\
\hline & $\mathrm{Ca}$ & $\mathrm{Mg}$ & $\mathrm{S}$ & $\mathrm{Ca}$ & $\mathrm{Mg}$ & $S$ \\
\hline & \multicolumn{3}{|c|}{$\mathrm{kg} \mathrm{ha}^{-1}$} & \multicolumn{3}{|c|}{$\mathrm{kg} \mathrm{ha}^{-1}$} \\
\hline Fontes de $\mathrm{Mn}$ & & & & & & \\
\hline Quelato & $9,46 \mathrm{a}$ & $9,87 \mathrm{~b}$ & $10,28 \mathrm{a}$ & 18,06 a & $16,37 \mathrm{~b}$ & $16,45 \mathrm{a}$ \\
\hline FTE BR 12 & $10,37 \mathrm{a}$ & $11,27 \mathrm{a}$ & $10,46 \mathrm{a}$ & $19,91 \mathrm{a}$ & 19,36 a & $17,37 \mathrm{a}$ \\
\hline Sulfato de Manganês & $9,62 \mathrm{a}$ & $9,21 \mathrm{~b}$ & $10,08 \mathrm{a}$ & $17,87 \mathrm{a}$ & $17,00 \mathrm{~b}$ & $17,29 \mathrm{a}$ \\
\hline \multicolumn{7}{|l|}{ Doses de $\mathrm{Mn}\left(\mathrm{kg} \mathrm{ha}^{-1}\right)$} \\
\hline 0 & 6,27 & 7,65 & 8,56 & 15,96 & 16,39 & 15,03 \\
\hline 2,5 & 9,72 & 10,20 & 9,72 & 17,66 & 17,04 & 16,81 \\
\hline 5,0 & 10,30 & 10,15 & 10,29 & 18,29 & 16,02 & 16,10 \\
\hline 7,5 & 10,27 & 10,45 & 10,90 & 21,27 & 19,13 & 18,88 \\
\hline 10,0 & 12,52 & 12,11 & 11,90 & 20,35 & 19,32 & 18,36 \\
\hline $\mathrm{CV}(\%)$ & 12,32 & 11,84 & 9,14 & 13,84 & 13,50 & 14,55 \\
\hline
\end{tabular}

Médias seguidas pela mesma letra, na coluna, não diferem entre si pelo teste de Tukey a 5\% de probabilidade.

Fonte: Elaboração dos autores.

Pode-se observar que mesmo o teor de Mn no solo estando médio, esse nutriente influenciou na absorção de Ca e Mg, sendo que Foy, Chaney e White (1978) mencionam que o manganês quando em excesso na solução do solo, promove reduções nas quantidades absorvidas de cálcio e magnésio pelas plantas, fato esse não ocorrido neste experimento.

Os valores extraídos de $\mathrm{S}$ para doses de $\mathrm{Mn}$ se ajustaram à regressão linear positiva para cana planta e cana soca (Figura 2c). Franco et al. (2008), avaliando o acúmulo da cultivar SP 81-3250 cana planta em duas regiões, verificaram acúmulo médio de $14,5 \mathrm{~kg}$ de $\mathrm{S}$ para 100 toneladas de colmos industrializáveis. A aplicação de sulfato de manganês pode ter influenciado no acúmulo de $\mathrm{S}$, devido a presença desse elemento em sua composição. Em cana soca ocorreu efeito significativo para doses de Mn no acúmulo de $\mathrm{Ca}$ e $\mathrm{Mg}$, com ajuste à regressão linear positiva, respectivamente (Figura 2d).

Tasso Junior et al. (2007), avaliando as variedades RB 85-5453; RB 85-5156; RB 83-5486; SP 89-1115 e IAC 91-2195 na região de Colina-SP, obtiveram médias acumuladas de 29,22; 29,18 e 15,70 $\mathrm{kg} \mathrm{ha}^{-1}$ de $\mathrm{Ca}, \mathrm{Mg}$ e $\mathrm{S}$, respectivamente. 
Figura 2. Interação de fontes e doses em cana planta para o acúmulo de $\mathrm{Ca}$ (a) e $\mathrm{Mg}$ (b), acúmulo de $\mathrm{S}$ em cana planta e cana soca (c) e acúmulo em cana soca de $\mathrm{Ca}$ e $\mathrm{Mg}$ (d) em função das doses de manganês na cultura da cana-deaçúcar. Suzanápolis-SP, 2009 e 2010.
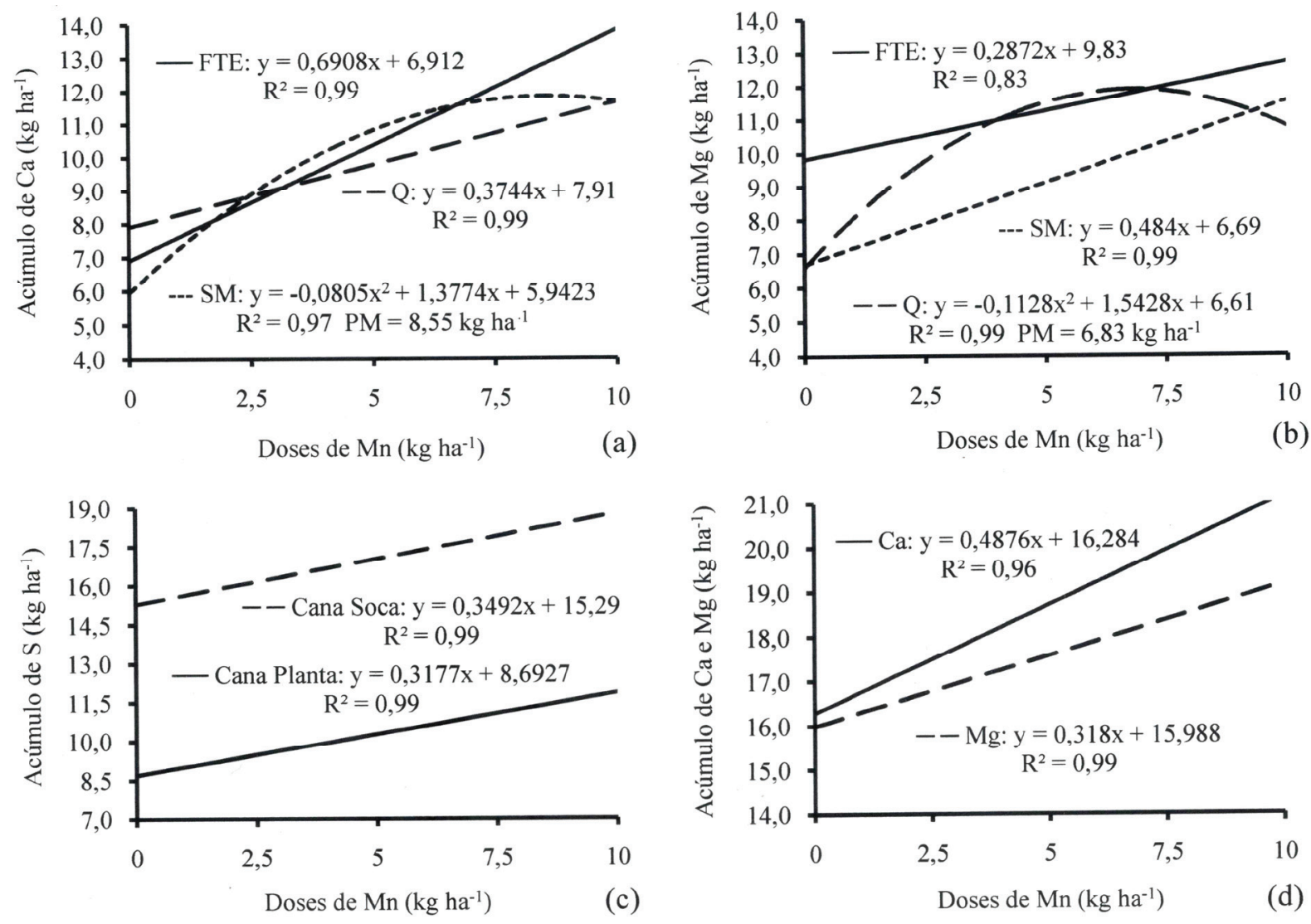

Fonte: Elaboração dos autores.

Quando se avaliaram os valores acumulados de micronutrientes (B, Fe, Mn e Zn) (Tabela 4) ocorreu efeito significativo para os valores de B, Fe e Zn em cana planta e valores de Zn em cana soca, onde a fonte FTE BR 12 proporcionou os maiores valores extraídos, diferindo das demais fontes de manganês. Esse fato pode ser devido à fonte utilizada conter $\mathrm{B}$ e $\mathrm{Zn}$ em sua formulação, ocorrendo efeito residual. O manganês e o ferro em condições ácidas são mais disponíveis para as plantas. Ambos ocorrem nos solos em mais de uma valência, dependendo do teor de umidade ou do estado de oxirredução do solo (OLIVEIRA et al., 2001).

Tasso Junior at al. (2007), trabalhando com vinte variedades de cana-de-açúcar em cana planta na região de Olímpia-SP, observou que a RB 86-7515 extraiu 1,4 $\mathrm{kg} \mathrm{ha}^{-1}$ de Mn e 2,3 $\mathrm{kg} \mathrm{ha}^{-1}$ de $\mathrm{Zn}$ para uma produtividade de 152 toneladas de colmos por hectare, sendo esses valores superiores aos obtidos neste trabalho com referência à produtividade de colmos.

Para as doses de Mn verificou-se efeito significativo para o acúmulo de $\mathrm{B}$ em cana planta (Figura 3a) e de Fe em cana soca (Figura 3b) com ajuste dos dados à regressão linear crescente. A relação $\mathrm{Mn}$ e $\mathrm{Fe}$ nos tecidos das plantas tem uma importante característica, tendo em vista que a toxidez de Mn está associada à deficiência de Fe (LEE, 1972) 
Tabela 4. Acúmulo médio de micronutrientes (B, Fe, Mn e Zn) nos colmos em função de fontes e doses de manganês na cultura da cana-de-açúcar. Suzanápolis-SP, 2009 e 2010.

\begin{tabular}{|c|c|c|c|c|c|c|c|c|}
\hline \multirow{3}{*}{ Tratamentos } & \multicolumn{4}{|c|}{ Cana planta } & \multicolumn{4}{|c|}{ Cana soca } \\
\hline & $\mathrm{B}$ & $\mathrm{Fe}$ & $\mathrm{Mn}$ & $\mathrm{Zn}$ & $\mathrm{B}$ & $\mathrm{Fe}$ & $\mathrm{Mn}$ & $\mathrm{Zn}$ \\
\hline & \multicolumn{4}{|c|}{$\mathrm{kg} \mathrm{ha}^{-1}$} & \multicolumn{4}{|c|}{$\mathrm{kg} \mathrm{ha}^{-1}$} \\
\hline \multicolumn{9}{|l|}{ Fontes de Mn } \\
\hline Quelato & $0,51 \mathrm{~b}$ & $1,30 \mathrm{~b}$ & $1,53 \mathrm{a}$ & $0,93 \mathrm{~b}$ & $0,42 \mathrm{a}$ & $1,43 \mathrm{a}$ & $2,14 \mathrm{a}$ & $0,64 \mathrm{~b}$ \\
\hline FTE BR 12 & $0,56 \mathrm{a}$ & $1,83 \mathrm{a}$ & $1,55 \mathrm{a}$ & $1,30 \mathrm{a}$ & $0,53 \mathrm{a}$ & $1,49 \mathrm{a}$ & $2,29 \mathrm{a}$ & $0,96 \mathrm{a}$ \\
\hline Sulfato de Manganês & $0,50 \mathrm{~b}$ & $1,06 \mathrm{~b}$ & $1,61 \mathrm{a}$ & $0,87 \mathrm{~b}$ & $0,53 \mathrm{a}$ & $1,51 \mathrm{a}$ & $2,00 \mathrm{a}$ & $0,61 \mathrm{~b}$ \\
\hline \multicolumn{9}{|l|}{ Doses de $\mathrm{Mn}\left(\mathrm{kg} \mathrm{ha}^{-1}\right)$} \\
\hline 0 & 0,44 & 1,40 & 1,28 & 0,76 & 0,51 & 1,34 & 1,94 & 0,64 \\
\hline 2,5 & 0,50 & 1,41 & 1,45 & 0,98 & 0,57 & 1,49 & 2,29 & 0,74 \\
\hline 5,0 & 0,52 & 1,54 & 1,53 & 1,06 & 0,48 & 1,35 & 2,30 & 0,71 \\
\hline 7,5 & 0,54 & 1,32 & 1,58 & 1,11 & 0,54 & 1,49 & 2,31 & 0,79 \\
\hline 10,0 & 0,63 & 1,31 & 1,97 & 1,26 & 0,40 & 1,71 & 2,30 & 0,79 \\
\hline CV $(\%)$ & 9,88 & 32,07 & 20,80 & 14,24 & 31,31 & 16,51 & 20,37 & 27,05 \\
\hline
\end{tabular}

Médias seguidas pela mesma letra, na coluna, não diferem entre si pelo teste de Tukey a 5\% de probabilidade.

Fonte: Elaboração dos autores.

Figura 3. Acúmulo médio de B em cana planta (a), Fe em cana soca (b) e de Mn (c) e Zn (d) na cana planta e cana soca em função das doses de manganês na cultura da cana-de-açúcar. Suzanápolis-SP, 2009 e 2010.
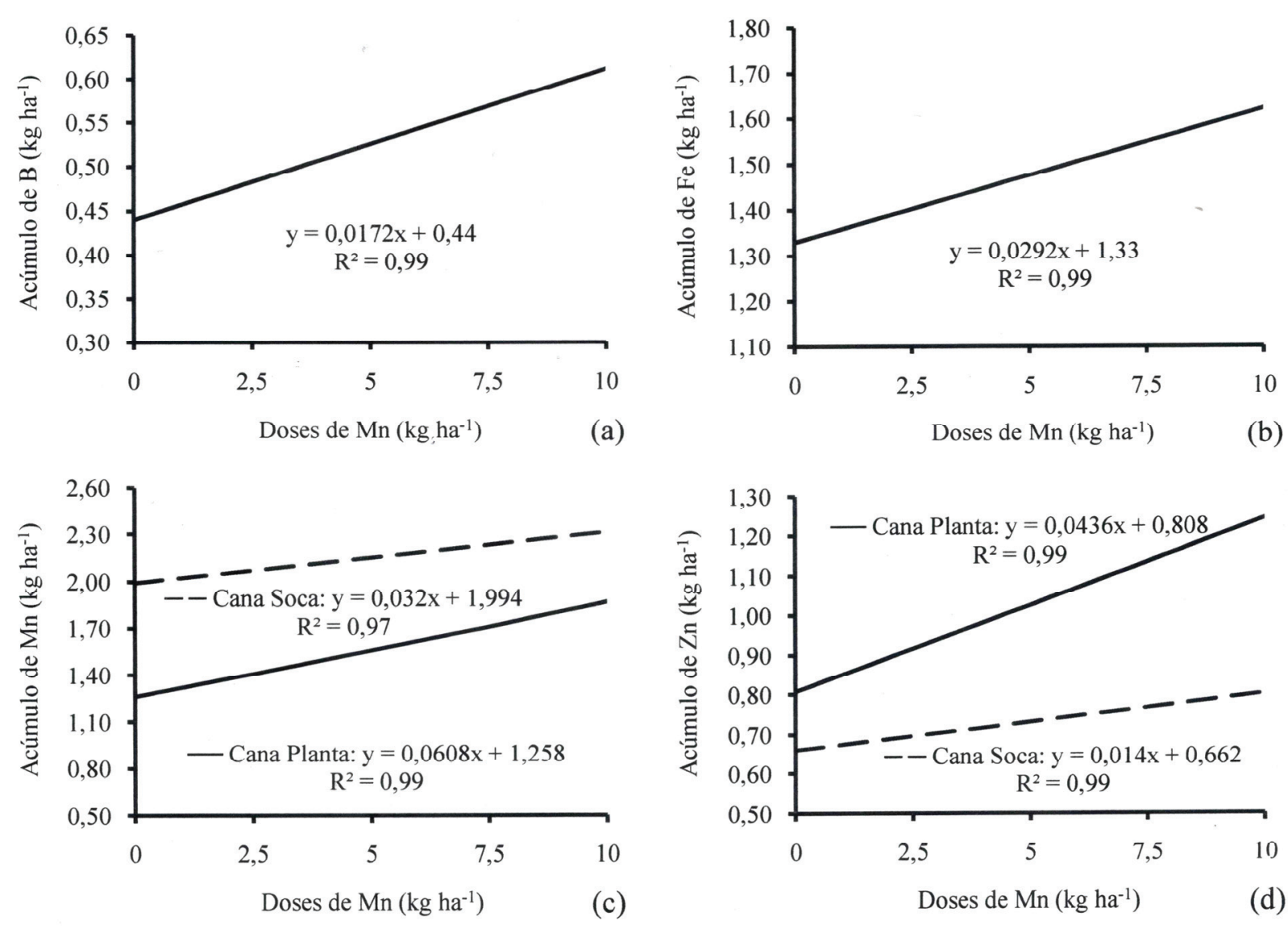

Fonte: Elaboração dos autores. 
Observou regressão linear crescente para o acúmulo de $\mathrm{Mn}$, sendo que quanto maior a dose de Mn aplicada, maior foi a quantidade acumulada pela planta (Figura 3c) e Zn (Figura 3d) em cana planta e cana soca, respectivamente.
Quando se avaliaram os valores da matéria seca do colmo e a produtividade de colmos industrializáveis da cana planta e cana soca (Tabela 5), em função das fontes Mn, não foram constatados efeitos significativos para nenhuma das variáveis.

Tabela 5. Valores médios de matéria seca do colmo (MSC) e tonelada de cana por hectare (TCH) em função de fontes e doses de manganês na cultura da cana-de-açúcar. Suzanápolis-SP, 2009 e 2010.

\begin{tabular}{|c|c|c|c|c|}
\hline \multirow{2}{*}{ Tratamentos } & \multicolumn{2}{|c|}{ Cana planta } & \multicolumn{2}{|c|}{ Cana soca } \\
\hline & $\operatorname{MSC}\left(\mathrm{t} \mathrm{ha}^{-1}\right)$ & TCH $\left(\mathrm{t} \mathrm{ha}^{-1}\right)$ & $\operatorname{MSC}\left(\mathrm{t} \mathrm{ha}^{-1}\right)$ & $\mathrm{TCH}\left(\mathrm{t} \mathrm{ha}^{-1}\right)$ \\
\hline \multicolumn{5}{|l|}{ Fontes de Mn } \\
\hline Quelato & $26,05 \mathrm{a}$ & $93,5 \mathrm{a}$ & $28,94 \mathrm{a}$ & $99,7 \mathrm{a}$ \\
\hline FTE BR 12 & $26,45 \mathrm{a}$ & 93,3 a & $29,71 \mathrm{a}$ & $101,6 \mathrm{a}$ \\
\hline Sulfato de Manganês & $24,35 \mathrm{a}$ & $88,7 \mathrm{a}$ & $29,89 \mathrm{a}$ & $97,3 \mathrm{a}$ \\
\hline \multicolumn{5}{|l|}{ Doses de Mn $\left(\mathrm{kg} \mathrm{ha}^{-1}\right)$} \\
\hline 0 & 21,57 & 87,4 & 26,05 & 90,1 \\
\hline 2,5 & 24,58 & 91,1 & 28,69 & 101,0 \\
\hline 5,0 & 25,88 & 87,5 & 29,25 & 104,7 \\
\hline 7,5 & 27,26 & 93,8 & 32,06 & 99,8 \\
\hline 10,0 & 28,79 & 99,2 & 31,53 & 101,9 \\
\hline CV (\%) & 8,39 & 15,67 & 8,83 & 15,38 \\
\hline
\end{tabular}

Médias seguidas pela mesma letra, na coluna, não diferem entre si pelo teste de Tukey a 5\% de probabilidade.

Fonte: Elaboração dos autores.

Observou-se interação entre fontes e doses de Mn para a matéria seca do colmo, sendo que as fontes FTE BR 12 e sulfato de manganês se ajustaram à regressão linear crescente (Figura 4a). Já os dados referentes à fonte quelato se ajustaram à regressão quadrática com ponto de máximo estimado em $9,17 \mathrm{~kg} \mathrm{ha}^{-1}$. Estes resultados são semelhantes aos obtidos por Carvalho, Andrade e Evangelista (1993) ao avaliarem o potencial produtivo das variedades CB 47-355, SP 70-1143, SP 71-1406, RB 72-454 e
NA 56-79 obtendo variação no acúmulo de matéria seca da parte aérea entre 30,47 a 36,35 t ha-1. As doses de Mn influenciaram a matéria seca de colmos em cana soca (Figura 4b), cujos dados se ajustaram à regressão linear crescente. Franco et al. (2009) trabalhando com doses de $\mathrm{Zn}\left(0,3\right.$ e $\left.6 \mathrm{~kg} \mathrm{ha}^{-1}\right)$ na variedade SP 81-3250 obtiveram produtividade de matéria seca de colmos de 37,2 e 33,5 $\mathrm{t} \mathrm{ha}^{-1}$ nas doses 0 e $6 \mathrm{~kg} \mathrm{ha}^{-1}$ de $\mathrm{Zn}$, respectivamente. 
Figura 4. Interação entre fontes e doses de manganês em cana planta na matéria seca de colmos (a) e valores médios da matéria seca de colmos em cana planta (b) em função das doses de manganês na cultura da cana-de-açúcar. Suzanápolis-SP, 2009 e 2010.
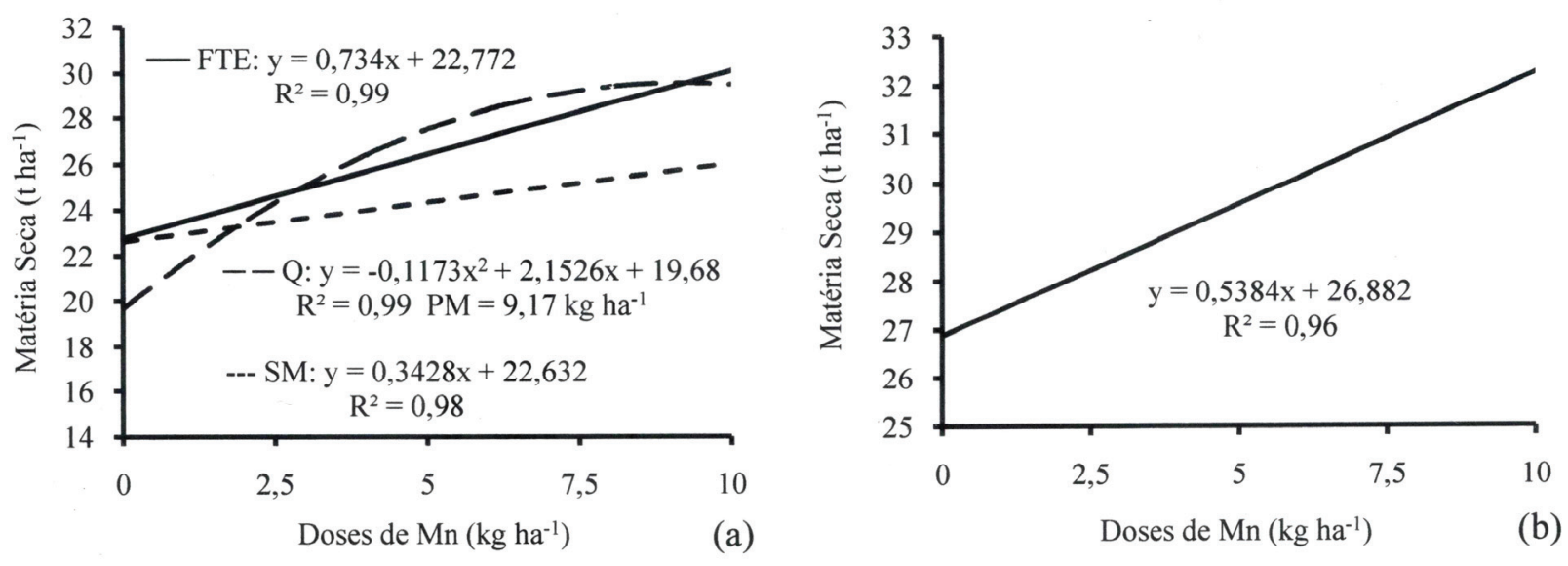

Fonte: Elaboração dos autores.

A produtividade de colmos não ajustou às regressões testadas, obtendo-se produtividades que variaram de 87 a 99 t ha $^{-1}$ na cana planta e de 90 a 104 t ha ${ }^{-1}$ na cana soca. Gava et al. (2008) verificaram, em estudo com três variedades de cana-de-açúcar em primeiro ciclo de cultivo na região de Jaú - SP, produtividades de 115,$8 ; 112,1$ e $91,9 \mathrm{t} \mathrm{ha}^{-1}$ para as variedades RB 86-7515, RB 85-5536 e SP 80-3280, respectivamente. Oliveira et al. (2008), estudando o comportamento de variedades de cana-de-açúcar em primeiro ciclo de cultivo na região de Carpina $\mathrm{PE}$, obtiveram produtividades médias de $87,6 \mathrm{tha}^{-1}$ para a RB 86-7515.

\section{Conclusões}

As fontes e doses de manganês influenciaram no acúmulo de macro e micronutrientes e na matéria seca de colmo em cana planta e cana soca.

A aplicação de fontes e doses de manganês ocasionou efeito residual na cultura da cana-deaçúcar.

A produtividade de colmos não foi influenciada pelas doses e fontes manganês em nenhum dos cultivos.

\section{Referências}

BARBOSA, M. H. P.; OLIVEIRA, M. W.; SILVEIRA, L. C. I.; DAMASCENO, C. M.; MENDES, L. C. Acúmulo e alocação de nutrientes pela RB72454 no ciclo da cana-planta. In: CONGRESSO NACIONAL DA SOCIEDADE DOS TÉCNICOS AÇUCAREIROS E ALCOOLEIROS DO BRASIL, 8., 2002, Recife. Anais... Recife: Sociedade dos Técnicos Açucareiros e Alcooleiros do Brasil, 2002. p. 264-267.

CARVALHO, G. J.; ANDRADE, L. A. B.; EVANGELISTA, A. R. Avaliação do potencial forrageiro de cinco variedades de cana-de-açúcar (ciclo de ano) em diferentes estádios de desenvolvimento. STAB - Açúcar, Álcool e Subprodutos, Piracicaba, v. 11, n. 4, p. 18-23, 1993.

CASARIN, V.; VILLA NOVA, V. S.; FORLI, F. Micronutrientes em cana-de-açúcar. In: MARQUES, M. O.; MUTTON, M. A. (Coord.). Tópicos em tecnologia sucroalcooleira. Jaboticabal: FUNEP, 2001. v. 1, p. 1-12.

COLETI, J. T.; CASAGRANDE, J. C.; STUPIELLO, J. J.; RIBEIRO, L. O.; OLIVEIRA, G. R. Remoção de macronutrientes pela cultura da cana-planta e cana-soca em Argissolos, variedades RB 835486 e SP 81-3250. STAB - Açúcar, Álcool e Subprodutos, Piracicaba, v. 24, n. 5, p. 32-36, 2006.

COLETI, J. T.; STUPIELLO, J. J.; OLIVEIRA, G. R.; CASAGRENDE, J. C.; RIBEIRO, L. D. Remoção de macronutrientes pela cana planta e cana soca, em argissolos, variedades RB83 486 e SP81 3250. 
CONGRESSO NACIONAL DA SOCIEDADE DOS TÉCNICOS AÇUCAREIROS E ALCOOLEIROS DO BRASIL - STAB. 8., 2002, Recife. Anais... Recife, Sociedade dos Técnicos Açucareiros e Alcooleiros do Brasil, 2002. p. 316-321.

COMPANHIA NACIONAL DE ABASTECIMENTO CONAB. Acompanhamento da safra brasileira: cana-deaçúcar, terceiro levantamento, dezembro/2011. Brasília, 2011. Disponível em: <http://www.conab.gov.br/ OlalaCMS/uploads/arquivos/11_12_08_11_00_54_08. pdf $>$. Acesso em: 13 jan. 2012.

EMPRESA BRASILEIRA DE PESQUISA AGROPECUÁRIA - EMBRAPA. Centro Nacional de Pesquisa de Solos. Sistema brasileiro de classificação de solos. Rio de Janeiro: Embrapa, 2006. 306 p.

FOY, C. D.; CHANEY, R. L.; WHITE, M. C. The physiology of metal toxicity in plants. Annual Review of Plant Physiology, Lancaster, v. 29, p. 511-566, 1978.

FRANCO, H. C. J.; CANTARELLA, H.; TRIVELIN, P. C. O.; VITTI, A. C.; OTTO, R.; FARONI, C. E.; SARTORI, R. H.; TRIVELIN, M. O. Acúmulo de nutrientes pela cana planta. STAB - Açúcar, Álcool e Subprodutos, Piracicaba, v. 26, n. 5, p. 41-45, 2008.

FRANCO, H. C. J.; TRIVELIN, P. C. O.; VITTI, A. C.; FARONI, C. E.; SARTORI, R. H. Produtividade e atributos tecnológicos da cana-planta relacionados à aplicação de zinco. STAB - Açúcar, Álcool e Subprodutos, Piracicaba, v. 27, n. 5, p. 30-34, 2009.

GAVA, G. J. C.; SILVA, M. A.; CRUZ, J. C. S.; JERÔNIMO, E. M.; OLIVEIRA, M. W.; KRONTAL, Y.; VERED, E.; AGUIAR, F. L.; PEDROSO, D. B. Produtividade e atributos tecnológicos de três cultivares de cana-de-açúcar irrigadas por gotejamento subsuperficial, In: CONGRESSO NACIONAL DA STAB, 9., 2008, Maceió. Anais... Maceió: STAB, 2008. p. $751-755$.

GOMES, J. F. F. Produção de colmos e exportação de macronutrientes por primários cultivares de cana-deaçúcar (Saccharum spp.). 2003. Dissertação (Mestrado em Agronomia - Solos e Nutrição de Plantas) - Escola Superior de Agricultura Luiz de Queiroz, Piracicaba.

LEE, C. R. Interrelationships of aluminum and manganese on the potato plant. Agronomy Journal, Madison, v. 64, n. 4, p. 546-549, 1972.

MALAVOlTA, E.; VITTI, G. C.; OlIVEIRA, S. A. Avaliação do estado nutricional das plantas: princípios e aplicações. 2. ed. Piracicaba: Associação Brasileira para Pesquisa da Potassa e do Fosfato, 1997. 319 p.

MAZAMBANI, A. E.; PINTO, A. S.; SEGATO, S. V.; MATTIUZ, C. F. M. História e morfologia da cana-de- açúcar. In: SEGATO, S. V.; PINTO, A. S.; JENDIROBA, E.; NÓBREGA, J. C. M. Atualização em produção de cana-de-açúcar. Piracicaba: CP 2, 2006. p. 11-18.

MENDES, L. C. Eficiência nutricional de cultivares de cana-de-açúcar. 2006. Dissertação (Mestrado em Fitotecnia) - Universidade Federal de Viçosa, Viçosa, MG.

OLIVEIRA, E. C. A. Dinâmica de nutrientes na canade-açúcar em sistema irrigado de produção. 2008. Dissertação (Mestrado em Agronomia - Ciência do Solo) - Universidade Federal Rural de Pernambuco, Pernambuco.

OLIVEIRA, E. C. A.; FREIRE, F. J.; OLIVEIRA, R. I.; FREIRE, M. B. G.; SIMÕES NETO, D. E.; SILVA, S. A. M. Extração e exportação de nutrientes por variedades de cana-de-açúcar cultivadas sob irrigação plena. Revista Brasileira de Ciência do Solo, Viçosa, v. 34, n. 4, p. 1343-1352, 2010.

OLIVEIRA, E. C. A.; OLIVEIRA, A. C.; OLIVEIRA, R. I.; COSTA, S. A.; SIMÕES NETO, D. E.; FREIRE, F. J. Rendimento de colmo e atributos tecnológicos de cultivares de cana-de-açúcar, plantadas no Nordeste, sob dois sistemas de irrigação, In: CONGRESSO NACIONAL DA STAB, 2008, Maceió. Anais... Maceió: STAB, p. 756-761, 2008.

OLIVEIRA, I. P.; KLUTHCOUSKI, J.; SANTOS, R. S. M.; FANCELLI, A. L.; DOURADO NETO, D.; FARIA, C. D. Concentrações residuais de cobre, ferro, manganês e zinco em Latossolo Roxo Eutrófico sob diferentes tipos de manejo. Pesquisa Agropecuária Tropical, Goiânia, v. 31, n. 2, p. 97-103, 2001.

ORLANDO FILHO, J.; ROSSETO, R.; CASAGRANDE, A. A. Cana-de-açúcar. In: FERREIRA, M. E. (Coord.). Micronutriente e elementos tóxicos na agricultura. Jaboticabal: CNPq/FAPESP/POTAFOS, 2001. v. 1, p. 355-373.

RAIJ, B. van; ANDRADE, J. C.; CANTARELLA, H.; QUAGGIO, J. A. Análise química para avaliação da fertilidade de solos tropicais. Campinas: Instituto Agronômico, 2001, 285 p.

RAIJ, B. van; CANTARELlA, H.; GUAGGIO, J. A.; FURLANI, A. M. C. Recomendações de adubação e calagem para o Estado de São Paulo. 2. ed. Campinas: Instituto Agronômico, 1997. 285 p. (Boletim técnico, 100).

SEGATO, S. V.; MATTIUZ, C. F. M.; MOZAMBANI, A. E. Aspectos fenológicos da cana-de-açúcar. In: SEGATO, S. V.; PINTO, A. S.; JENDIROBA, E.; NÓBREGA, J. C. M. Atualização em produção de cana-de-açúcar. Piracicaba: CP 2, 2006. p. 19-36. 
SILVA, L. C. Análise de crescimento e acúmulo nutrientes de sete cultivares de cana-de-açúcar na Região de Coruripe. 2007. Dissertação (Mestrado em Produção Vegetal) - Universidade Federal de Alagoas, Alagoas.

TASSO JUNIOR, L. C.; MARQUES, M. O.; CAMILOTTI, F.; SILVA, T. Extração de macronutrientes em cinco variedades de cana-de-açúcar cultivadas na região centro-norte do estado de São Paulo. STAB Açúcar, Álcool e Subprodutos, Piracicaba, v. 25, n. 6, p. 6-8, 2007.
VAZQUEZ, G. H.; SANCHES, A. C. Formas de aplicação de micronutrientes na cultura da cana-deaçúcar. Nucleus, Ituverava, v. 7, n. 1, p. 267-276, 2010.

VITTI, G. C.; OLIVEIRA, D. B.; QUINTINO, T. A. Micronutrientes na cultura da cana-de-açúcar. In: SEGATO, S. V.; PINTO, A. S.; JENDIROBA, E.; NÓBREGA, J. C. M. Atualização em produção de canade-açúcar. Piracicaba: CP 2, 2006. p. 121-138.

ZONTA, E. P.; MACHADO, A. A.; SILVEIRA JÚNIOR, P. Sistema de análise estatística para microcomputadores: manual de utilização. 2. ed. Pelotas: UFPEL, 1987. 